\title{
Proximal migration of pancreatic stent: placement of smaller stent within another stent for retrieval
}

\section{A 22-year-old man presented with ob-} structive jaundice. His workup revealed cholelithiasis and obstruction of the lower end of the common bile duct (CBD) by a stone. He underwent endoscopic retrograde cholangiopancreatography (ERCP) elsewhere; the CBD was cleared, and a 7-Fr pancreatic stent was placed to prevent pancreatitis arising from repeated pancreatic duct cannulation. The pancreatic stent was found to have migrated proximally at 1 week and the patient was referred to us. Pancreatic imaging showed the stent deep in the pancreatic duct (distal to the genu) ( Fig. 1). Stent retrieval was attempted with a biliary stone extractor balloon, foreign body forceps, basket and snare, however, the stent could not be retrieved. A guidewire was placed through the stent and a 5-Fr stent was placed within it, with the distal end in the duodenal lumen ( $\bullet$ Fig. 2). At a repeat attempt at endoscopic retrieval after 3 days, the smaller stent was pulled out with a snare and the initial, displaced stent came out along with the smaller stent.

Proximal migration of pancreatic stent occurs in nearly $5.2 \%$ of cases and is more common in patients with dysfunction of the sphincter of Oddi or with stent length $>7 \mathrm{~cm}$ [1]. If the migrated stent is not retrieved, it may cause stricture of the duct and irreversible loss of pancreatic function [2]. Usually traction is applied for stent retrieval, using a biliary stone extractor balloon or a stent-pulling device, which draws the migrated stent into the duodenal lumen. Various devices that can be used for stent retrieval are the biliary stone extractor balloon, foreign body grasp forceps, snare, basket, Soehendra stent retriever, SpyGlass assistance, and interventional cardiology accessories. In difficult cases surgery may be considered [3]. A second stent placed within the migrated stent provides traction from within, which might aid in pulling the migrated stent to the duodenum. In conclusion, in this article, we have described a novel method for retrieval of a migrated pancreatic stent, although this method is not applicable for 5-Fr stents.

\section{Endoscopy_UCTN_Code_TTT_1AR_2AZ}

\section{Competing interests: None}

\section{N. S. Choudhary, R. Puri, R. Sud}

Institute of Digestive and Hepatobiliary

Sciences, Medanta, The Medicity,

Gurgaon, NCR Delhi, India

\section{References}

1 Johanson JF, Schmalz MJ, Geenen JE. Incidence and risk factors for biliary and pancreatic stent migration. Gastrointest Endosc 1992; 38: 341 - 346

2 Bakman YG, Safdar K, Freeman ML. Significant clinical implications of prophylactic pancreatic stent placement in previously normal pancreatic ducts. Endoscopy 2009; 41: 1095-1098

3 Gong B, Sun B, Hao LX et al. Usefulness of an algorithm for endoscopic retrieval of proximally migrated $5 \mathrm{Fr}$ and $7 \mathrm{Fr}$ pancreatic stents. Hepatobiliary Pancreat Dis Int 2011; 10: $196-200$

\section{Bibliography}

DOI http://dx.doi.org/

10.1055/s-0033-1344564

Endoscopy 2014; 46: E132

(c) Georg Thieme Verlag KG

Stuttgart · New York

ISSN 0013-726X

\section{Corresponding author}

\section{R. Puri}

Institute of Digestive and Hepatobiliary Sciences

Medanta, The Medicity

Gurgaon

NCR Delhi

India

purirajesh69@gmail.com

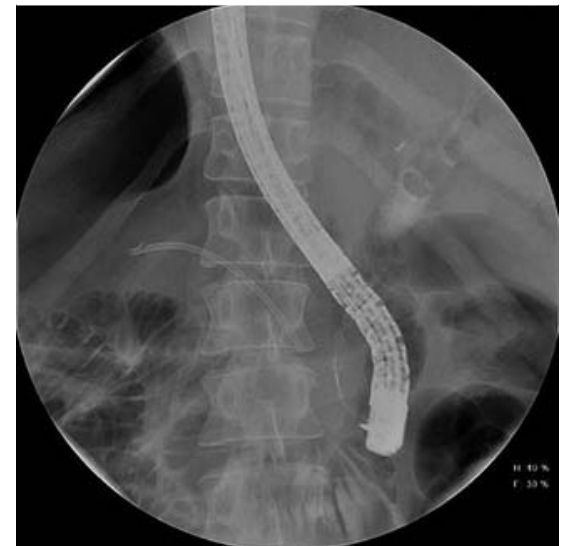

Fig. 1 Fluoroscopic view showing a migrated pancreatic stent in a 22-year-old man with obstructive jaundice.

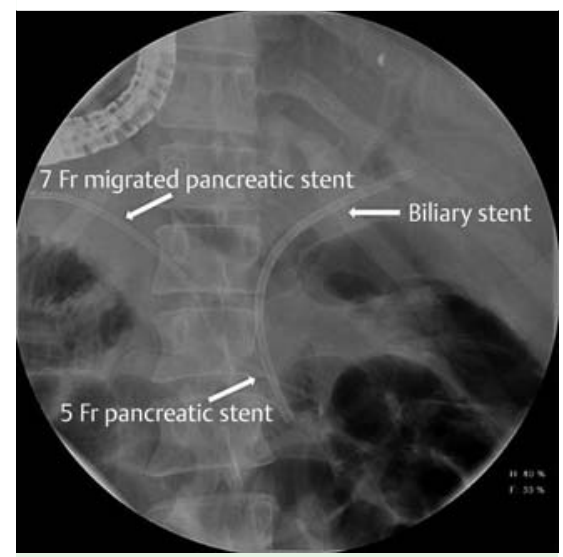

Fig. 2 Fluoroscopic view showing the $5-\mathrm{Fr}$ pancreatic stent. The proximal end is not visible as it is inside the migrated 7-Fr stent. 